\title{
How Access to Internet Affects Cadets' Learning Process in STIP Jakarta
}

\author{
P Sijabat $^{1}$, P N F L Batu ${ }^{2}$, T F Kalangi ${ }^{3}$, Bagaskoro ${ }^{4}$ \\ \{pande.sijabat@gmail.com1,nancy.lumbanbatu@gmail.com², franskalangi@gmail.com ${ }^{3}$,bagaskorostip@ \\ gmail.com $\left.{ }^{4}\right\}$ \\ ${ }^{1,2,3,4}$ STIP (Sekolah Tinggi Ilmu Pelayaran) Jakarta, Indonesia
}

\begin{abstract}
Internet has been acknowledged as the source of information, all kinds of it. Especially in education, it is resourceful both for the students and teachers. The use of the internet as an aid to education is also applied in our maritime academy in Jakarta. Providing access to the internet for students, called cadets, is relatively new on the premises. This study is intended to find out how the cadets access the internet and how their access to the internet gives impact to the process and eventually the result of their studies. This quantitative study is conducted by distributing online questionnaire. Data was collected from 240 respondents as sample and analyzed using Pearson correlation formula. At level of significance 0.01 , the results are as follow: there is a positive and significant correlation between the intensity of internet usage and the cadets' achievement with $\mathrm{R}$ correlation $=0.701$; there is also a positive and significant correlation between the availability of internet access and the achievement with $R$ correlation $=0.453$. Keywords: level of customer satisfaction, service quality, gap analysis.
\end{abstract}

Keywords: Internet, access, maritime, cadet, achievement

\section{Introduction}

Academics in Indonesia are one of the earliest parties to use the internet (Febrian, 2003). The internet is an alternative source to meet scientific information needs that support academic needs. This is because the internet can provide up-to-date information, making it easy to get the required documents[1].

When browsing, most internet users use its mobile device (smartphone) by 89, 9 million or $67.8 \%$. Of course, this should be the concern of website owners to create a website mobilefriendly or responsive. While the most widely used browser is Google Chrome amounting to $66,6 \%$. This is certainly understandable because most smartphones use Google's Android operating system.

These statistical data are very important for business people, entrepreneurs or online sales owners to determine the target of prospective cadets.

In the world of education the Internet is very useful as a media that helps in completing the teaching and learning process, both in learning media, completing assignments for students/cadets[2], means to improve skills, communication and as a media source of information can even be analogous to the world's giant library. can be used by Midshipmen of the College of Shipping Sciences to help find information related to learning material and research assignments, even as a means of communication between cadets[3]. 
The needs of cadets for information can be obtained either through the internet[4]. However, there are various factors that cause cadets to meet the need for information. The main problems that are interesting to study are what facilities and infrastructure are used by STIP cadets to access the internet, what factors influence, the extent to which internet access has been used, a positive and significant relationship between internet usage and the GPA and the learning process in the environment campus.

The question that then arises is whether the availability of the internet network affects cadets' academic performance? In more detail, the problems in this study are:

the facilities and infrastructure are used by STIP cadets to access the internet, the factors influence internet usage among STIP cadets, how far is the use of internet access provided by STIP or its partners, if there is a positive and significant correlation between internet usage and the cadets' index of achievement, and if there is a positive and significant relationship between internet usage and learning processes within the STIP campus[5].

\section{Literature review}

\subsection{Internet as an Information Source}

Internet (known as name information superhighway) stands for inter-networking. In accordance with its stands, the internet consists of a group of computer networks belonging to companies, institutions, government agencies, or network service providers (ISP/internet service providers ) that are interconnected where each computer network is managed independently. The development of the Internet itself has actually been initiated since the 1960s as a project of the United States defense department. The internet has become one of the media that has become the most popular source of information among college cadets in the world. A source of information according to Murtonen is a trusted carrier of information and can provide satisfaction in meeting information needs[6]. Use of the Internet has become a way of life (lifestyle) for a large part of Taruna universities throughout the world. For them the internet is a functional tool that has changed the way someone interacts with other people, as well as in finding information. Many of the cadets use the internet to complete various academic interests, both through e-mail exchanges with faculty, peers, or other interests. Besides that, Taruna also accesses on-line catalogs, bibliographic databases, and other sources of information in the form of graphics, text, and images through the world wide web (WWW)[7]

Usun [7] revealed that the internet appeals to students in higher education for a number of reasons, namely: (1) reducing the time lag between production and utilization of knowledge; (2) promote international cooperation and opinion; (3) various information; and (4) promoting multidisciplinary research.

Increasing the information needs of the information society, especially the academic community is felt to be increasing due to the interrelationships and individual dependence on information. Among the many human needs, the most striking need for improvement is the need for information. Therefore the selection of information sources determines someone to fulfill their needs. In addition, the selection of one's information source is also based on habitual patterns. Meyers, Nathan, and Saxton (2006) state that habit patterns are interpreted if in the past a source of information can meet a person's needs then he will tend to use the source of information for the next time[8]. adds that one's knowledge of resources (awareness of information sources) will be used, such as the speed of access (accessibility), quality (quality), timeliness (timeliness), confidence (trustworthiness), habits (familiarity ) and 
previous success ( previous success ) will directly affect the implementation of information retrieval ( information is sought). So this is what encourages someone to choose the right media as a source of information for meeting their needs.

\subsection{Internet facilities}

Until now there is a various example of service Internet used to search for or get information from the internet. Without this service then the Internet will not be as useful as it is today. Because the admin will discuss various types service Internet maybe you don't know what you can do when you get access to the internet.

Service Internet can be obtained from paid or free, there are also services the Internet the paid ones are indeed made to help friends to solve a problem. There is also service Internet which is used as entertainment or education. And the most recent is service Internet can be used as a livelihood. almost all types of services the Internet this helps friends get information.

\subsection{Example service Internet to date}

Service Internet currently dominated by Google services, there are many Google services that help friends find information in cyberspace. starting from search engines, e-mail services, data storage and much more.

\section{a. Search Engine}

The first is the search engine. Admin deliberately enters the search engine at the top, because of the search engine is service Internet the most important at the moment. A search engine is a service Internet which is used to search for everything that is on the internet, can news, articles and all kinds.

The main task of the search engine is storing all information on all websites that are currently available so that users can easily find all kinds of information in the form of documents, images, applications and so on. Currently the main search engine is Google or bing.

b. E-mail (electronic correspondence)

Email or electronic email is a service Internet which has been around since the beginning internet is used. Email is a message that contains text, files, images sent to certain individuals or groups of individuals using computer networks.

c. E-Banking (Internet banking)

E-banking services can be regarded as all banking processes carried out electronically, this service is like transferring data between accounts that are done using online internet media. So you don't need to use an ATM or through a bank, but just use your smartphone or laptop.

Besides the transfer process between accounts. E-banking can also be used to check balances. Check your finances like incoming funds or get out. Almost all conventional banks currently use e-banking services.

d. E-Learning (online learning)

E-learning is a learning process electronically, and generally uses computers to provide a portion, or the entire teaching and learning process, in schools, training, or distance learning programs.

e. Social Media

Social media is online communication that is made to interact with each other, share content by fellow users. Websites and applications dedicated to forums, microblogging, social networking, social bookmarking, and wikis are one type of social media. 


\subsection{Benefits of the Internet}

Quarterman and Mitchell in Herring[9], share the benefits of the internet in four categories, namely: 1). The internet as a communication medium is the most widely used internet benefit where every internet user can communicate with other users from all over the world; 2). Data exchange media, using e-mail, newsgroups, FTP, and www (World Wide Web - network websites) Internet users can exchange information quickly and cheaply; 3). Media to look for information or data, rapid internet development, makes www as one of the most important and accurate sources of information; 4). The benefits of the community, the internet has formed a new society consisting of internet users from all over the world. In this community internet users can communicate, find information, shop, conduct business transactions and so on. Because the nature of the internet is similar to our everyday world, the internet is often referred to as cyberspace or virtual world.

Meanwhile, according to Raharjo ), there are several other benefits from internet users, namely: 1). Interactive communication: The internet allows the creation of rapid communication between a user and other users without recognizing the limits of space and time, in addition to this, the internet can also save on communication costs incurred. Applications on the internet that can be used as communication tools are as follows: e-mail, video, conferencing, internet relay, and internet phone; 2). Askes to experts: The internet eliminates space and time limits so that one can communicate with experts elsewhere. A user or cadet can easily learn to experts in certain fields of science. Many experts are happy to answer questions sent by the audience; 3). Access to the library: Library collection is not limited to printed books and journals collection, but has become a center for disseminating information and bases as a tool for research and development of knowledge.

Through the internet network, researchers who are involved in the world of research can create associations between them to be able to communicate with each other.

\subsection{Media collaboration}

Collaboration or collaboration between parties involved in the field of education can occur more easily, efficiently, and cheaper. This collaboration can involve members from various fields of science spread across various countries in the world. The internet is a medium that is very helpful for collaboration which is usually hampered by space and time.

\section{a. Internet activity}

Horrigan[10] classified internet activities carried out by internet users into four internet usage interest groups, namely: a). E-mail; b). Fun activities, namely activities that are for fun or entertainment such as online for fun, video or audio clips, short messages, listening or downloading music, playing games, chatting; c). Information utility, namely internet activity to search for information, such as product information, travel information, weather, information about films, music, books, news, schools, health, government, finance, employment, and information about politics; d). Transactions, namely transaction activities (buying and selling) through the internet such as: buying something, ordering travel tickets, online banking.

b. Internet Usage Intensity

The intensity of one's internet usage according to Horrigan [10], there are two basic things that need to be observed, namely the frequency of the internet that is often used and the length of time that is used each time accessing the internet by internet users. 
The Graphic, Visualization \& Usability Center, the Georgia Institute of Technology, classified internet users into three categories based on the intensity of the internet used: 1). Heavy users: Internet users spend more than 40 working hours per month. This type of internet user is one of the characteristics of internet users who are addicted; 2). Medium users: internet users who spend between 10 to 40 hours per month; 3). Light users: internet users who spend less than 10 hours per month.

c. Cadets' Pattern in Using the Internet

Internet users are not only limited but also include the general public. The internet is not only used for research or academic activities, but also other activities, such as trading and business (now known as e-commerce ), seeking information about the world of entertainment, playing games, chatting, learning activities or as a medium for learning ( Computer-Assisted Learning Instruction / CAI), preaching, and others.

The advantages of the internet that do not recognize geographical boundaries also make the internet an ideal means for conducting distance learning activities, both through written and lecture courses (Febrian, 2003). This is also evidenced by the presence of computers with the Computer-Assisted Learning Instruction (CAI) program that functions as a teacher in helping students learn something. The existence of CAI is expected to expand the possibilities of education by overcoming distance and time so that various opinions for the solution of a problem can be obtained from a distant place in a relatively fast time.

Internet use by STIP cadets is mainly based on correspondence motives, followed by motives for seeking non-academic information, and motives for seeking academic information. Most STIP cadets are more satisfied on the internet compared to satisfaction with other media in seeking academic information than the literature obtained from the library, but STIP cadets have not utilized the potential of the internet as an optimal learning support media.

The reason for STIP cadets when they first used the internet was educational reasons, the importance of using the internet for personal communication, games, and access to public information. The cadets are classified as active internet users and it is known that the intensity of internet use by active users who use e-learning applications, personal e-mail, the world wide web, software /film/music downloads, and social media tends to have a higher intensity of internet usage compared to internet users who use other applications. Midshipmen who access the internet through campus or internet cafes tend to be classified as active users[11].

Cadets' pattern in using the internet is also influenced by individual factors and campus environmental factors in STIP. Individual factors consist of ownership of facilities and infrastructure, while campus environment factors are, factors of the location of internet usage, internet usage time, lecture material assignments. In addition, environmental factors can also consist of the presence of other people and other mass media. The existence of other people here refers to someone who is close (friend, brother, or sister) where simultaneously accessing the internet with the cadet.

Internet media functions for individuals can be seen from several things, namely: satisfaction, pleasure, and use, which reflects a certain level of order and predictability.

The internet function for individuals can be seen from the function of mass media for individuals, namely:

a. Information. The function of mass media as information concerning: Search for news about events and conditions related to the nearest environment, society and the world seek guidance regarding a variety of practical problems, opinions, and matters relating to choice determination satisfying curiosity and interest in general interest.

b. self-learning and education gain a sense of peace through the addition of knowledge. 
c. Personal identity concerns: find support for personal values, find behavioral models, identify yourself with other values (in the media) increase understanding of yourself.

d. Integration and social interaction: gain knowledge about the situation of others; social empathy, identify with others and increase ownership, find material for conversation and social interaction get friends, help run a social role allows someone to be able to contact family, friends, and society.

e. Entertainment: break away from problems, relax obtain mental and aesthetic pleasure, fill timem Emotional distribution.

\section{Method}

The type of research used in this study is quantitative with descriptive method. Descriptive method is research that is intended to provide an overview of a particular social reality, where information about it already exists even though it is not detailed and complete. Descriptive types are chosen because descriptive research is a type of research that provides a description or description of a situation as clearly as possible without any treatment of the object under study. While there are those who state that the purpose of descriptive research is to describe systematically and accurately about the facts and characteristics of the population or about a particular field. Questionnaires are used in the data collection process. The questionnaire is a list of structured questions with alternative answers available so that the respondent just has to choose the answer according to his aspirations, perceptions, attitudes, circumstances or personal opinions. The procedure in data collection is done by providing alternative answers in the questionnaire with the aim of limiting relevant answers, not intending to trap respondents. These restrictions are intended to facilitate data tabulation and analysis.

\subsection{The location in this study was at the Jakarta School of Shipping Sciences.}

The population in this study was the Midshipman of the Jakarta College of Shipping Sciences. Their needs in choosing information sources, both for the need to support their academic or other needs in order to improve their quality and also the quality of the university that shelves them.

The samples taken in this study were the Midshipman of the Jakarta School of Shipping Sciences Diploma IV Level I, II and Level IV Department of Nautics, Engineering and Management of Sea and Port Transportation (KALK).

To obtain respondents, multistage random sampling is used. The multilevel random withdrawal technique is the development of randomized clusters, the first random cluster is not randomized over individuals but in clusters where individuals are located. From these groups, individuals are selected.

In a random cluster that will be used by researchers there are sampling steps as follows:

a. Determine the first Unit or Unit first by taking samples, namely the Nautical Department, Marine Engineering and KALK where the unit is referred to as the Primary Sampling Unit of the PSU.

b. The next stage of the 3 departments in STIP Jakarta was randomly assigned to determine the sample expected in this study. From the random process, the results were obtained, namely each department was represented by level II, II and IV students.

c. Determination of Respondents using the Yamane Formula. In planning samples using the Yamane, formula can provide a representative weight so that calculations can be made 
with certainty the number of samples for a particular population. This formula is used because the population has a character that is difficult to describe.

Total Population:

$\mathrm{N}=$ Total TaunaTk I + Tk.II + Tk. IV $=\ldots . .$.

Calculated for each department.

Taro Yamane formula :

Information :

$\mathrm{n}=$ Number of samples

$\mathrm{N}=$ Total population

$\mathrm{d}=$ the desired level of significance (generally 0,05 for the non-exact field and 0.01 for the exact field).

Findings

\subsection{Characteristics of Respondents}

The description of the research object was obtained from the results of a questionnaire distributed for research to cadets in the STIP Jakarta environment which was the subject of research. The basic characteristics/identities of respondents asked in the questionnaire are names (may be filled in / not), gender, level of education which can be described in the tables below.

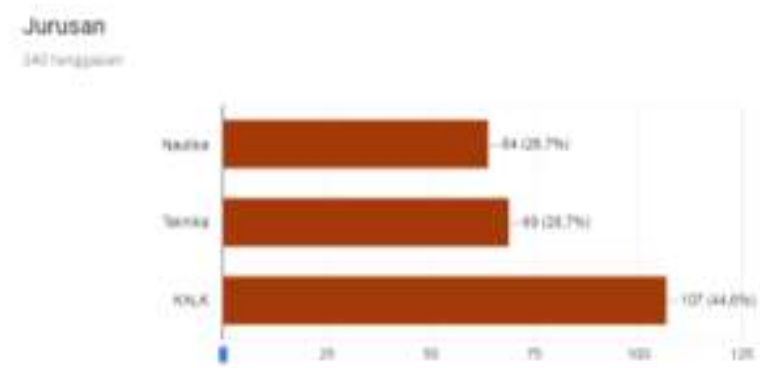

Figure 1: Respondents based on Their Department

Based on the data above shows that whole thing respondent represent from three department with $26.7 \%$ majors Nautika, $28.7 \%$ of majors Marine Engineering and $44.6 \%$ of the KALK Department. 

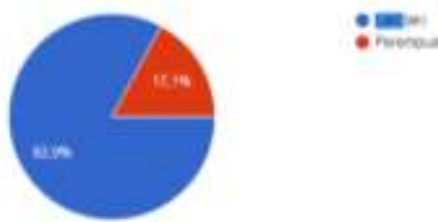

Figure 2: Respondents based on Their Sexes

Based on the data above shows that of all respondents represent cadets with total Percentage of $82.9 \%$ male and $17.1 \%$ female.

Mempunya: Tablet
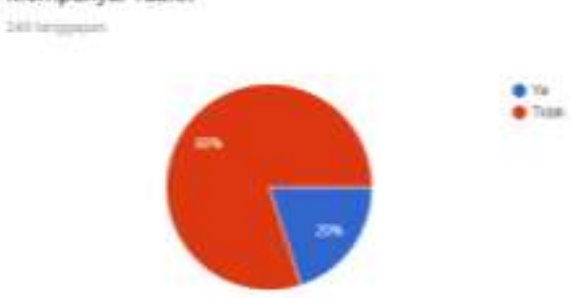

Figure 3: RespondentsWhoHaveTablets

Based on the data above shows that still low use Internet access with use of a tablet is only $20 \%$ of the respondents.

Mempunyai Smartphone
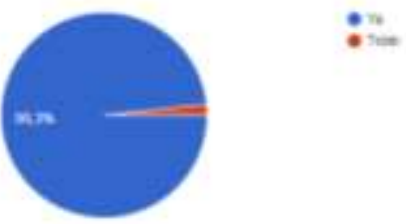

Figure 4: RespondentsWhoOwnSmartphones 
Based on the data above shows that the height is ownership and Smartphone usage a means access the internet with data $98.3 \%$ have Smartphones and1.7\%No have a Smartphone.

Mempunyai Modern
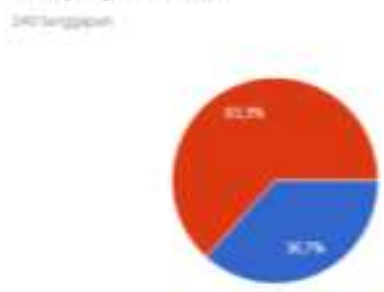

Figure 5: RespondentsWhoHaveModems

Based on the data above shows that Stillt here is desire own have means Internet access besides those already provided that is, $36.7 \%$ have a modem, $63.3 \%$ no have a modem.

Nal ip Terakhir

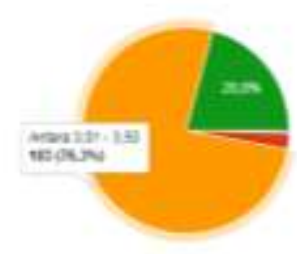

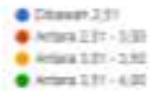

Figure 6: Respondents' GPA

Based on the data above shows that domination cadets' GPA value of $76.3 \%$ of respondents between value 3.0 - 3.5 while $20.8 \%$ of respondents between value 3.51 4.00 .

\subsection{Descriptive Statistics of Research Variables}

In this study using a questionnaire in data collection. Questionnaires are a number of written questions that are used to obtain information from the respondent in the sense of reports about the person and scope of work, or things he knows. The purpose of the questionnaire used in this study was to determine whether or not there was and how much 
influence the internet had available, internet access facilities and infrastructure, internet usage factors and the intensity of internet usage on learning outcomes at STIP Jakarta.

The study was conducted at STIP Jakarta, the authors submitted a set of questionnaires to respondents, namely cadets at STIP Jakarta, amounting to 240 people. This questionnaire consisted of 37 items representing 5 variables studied. The five research variables in the form of questionnaires are available internet variables (X1), facilities and infrastructure for internet access (X2), internet usage factors (X3), intensity of internet usage (X3) and learning outcome variables (Y). The process of analyzing respondents' data on available internet variables, internet access facilities, and infrastructure, internet usage factors, intensity of internet use and learning outcomes was carried out using the interval/weight approach.

Data description in this section includes $\mathrm{Y}$ variable data (learning outcomes) as dependent variable (endogenous), variable X 1 (internet available), variable X 2 (internet access facilities and infrastructure), variable X 3 (internet usage factors) and X 4 (intensity of internet usage) as independent variables (exogenous). Descriptions of each variable are presented in succession starting with variables $\mathrm{Y}, \mathrm{X} 1$, X 2 and X 3 .

The description of the research data of the three variables is expressed in the mean score

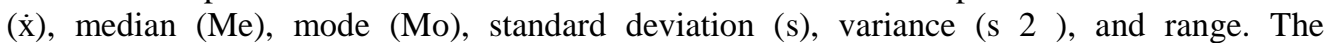
description of each variable is presented in full starting from variable $\mathrm{Y}, \mathrm{X} 1, \mathrm{X} 2 \mathrm{X} 3 \mathrm{X} 4$, as in Table 1 below:

Table 1: Summary Description Research Data Statistics

Descriptive Statistics

\begin{tabular}{|c|c|c|c|c|c|}
\hline & $\mathrm{N}$ & um Minim & um & Mean & on \\
\hline Internetygavailable & 240 & 13.00 & 20.00 & 18.30 & 1,71968 \\
\hline $\begin{array}{l}\text { Meansandinfrastructureinternetac } \\
\text { cess }\end{array}$ & 240 & 15.00 & 45.00 & $42^{31,30}$ & 7,00293 \\
\hline Factorinternetusage & 240 & 17.00 & 65.00 & $33^{53,68}$ & 9,05768 \\
\hline Intensityinternetusage & 240 & 6.00 & 20.00 & $33^{17,53}$ & 2,56116 \\
\hline Resultslearn & 240 & 9.00 & 35.00 & $92^{31,77}$ & 4,49607 \\
\hline Valid N (listwise) & 240 & & & & \\
\hline
\end{tabular}

Based on table 4.1 above, shows the mean value on available internet variables where the mean is 18,3042 with a standard deviation of 1,71968 , while the highest statement is 20 with the lowest statement of 13. The mean value of facilities and infrastructure is internet access where the mean is 31.3042 with a standard deviation of 7.00293 while the highest statement is 45 with the lowest statement of 15 .

The mean value on the internet use factor variable where the mean is 53.6833 with a standard deviation of 9.05768 , while the highest statement is 65 with the lowest statement of 17. The mean value in the internet usage intensification variable where the mean is 17.5333 with a standard deviation of 2.56116 while the highest statement is 20 with the lowest statement of 6 . The mean value of the learning outcome variable where the mean is 31.7792 with a standard deviation of 4.49607 while the highest statement is 35 with the lowest statement of 9 . 
The following graph for each variable:

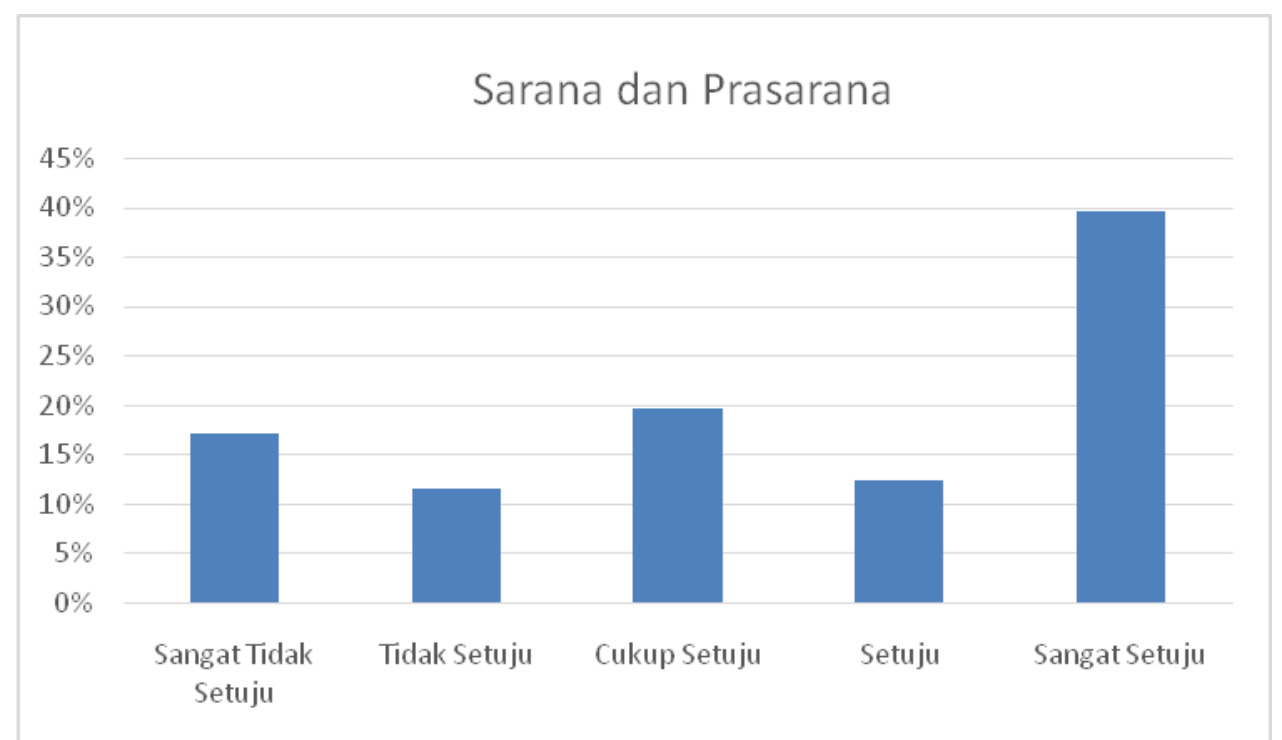

Figure 7: Facilities and Infrastructure to Learning Activities on Campus

From the results of the research, filling out respondents' questionnaires shows statistical data that the facilities and infrastructure of internet access are very supportive in improving the learning of cadets at the School of Shipping Sciences.

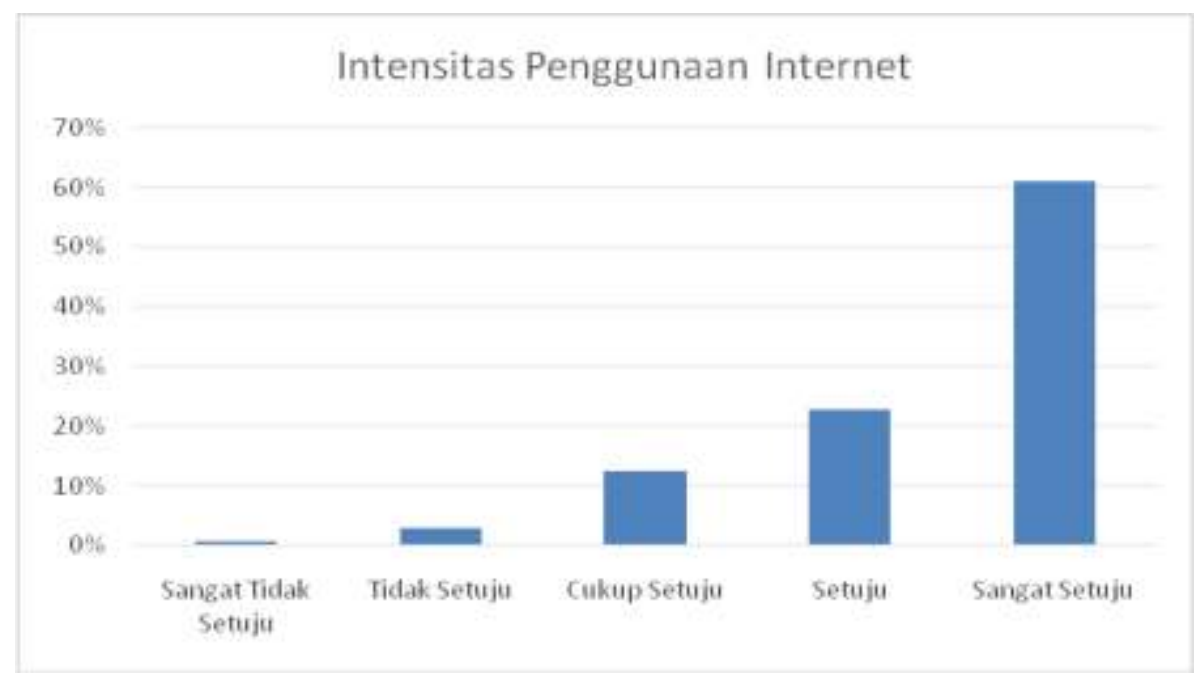

Figure 8: Intensity of Internet Usage 
From the results research charging questionnaire that intensity internet usage in the learning process sand looking for inside data information lecture of cadets in the STIP environment tend to increase.

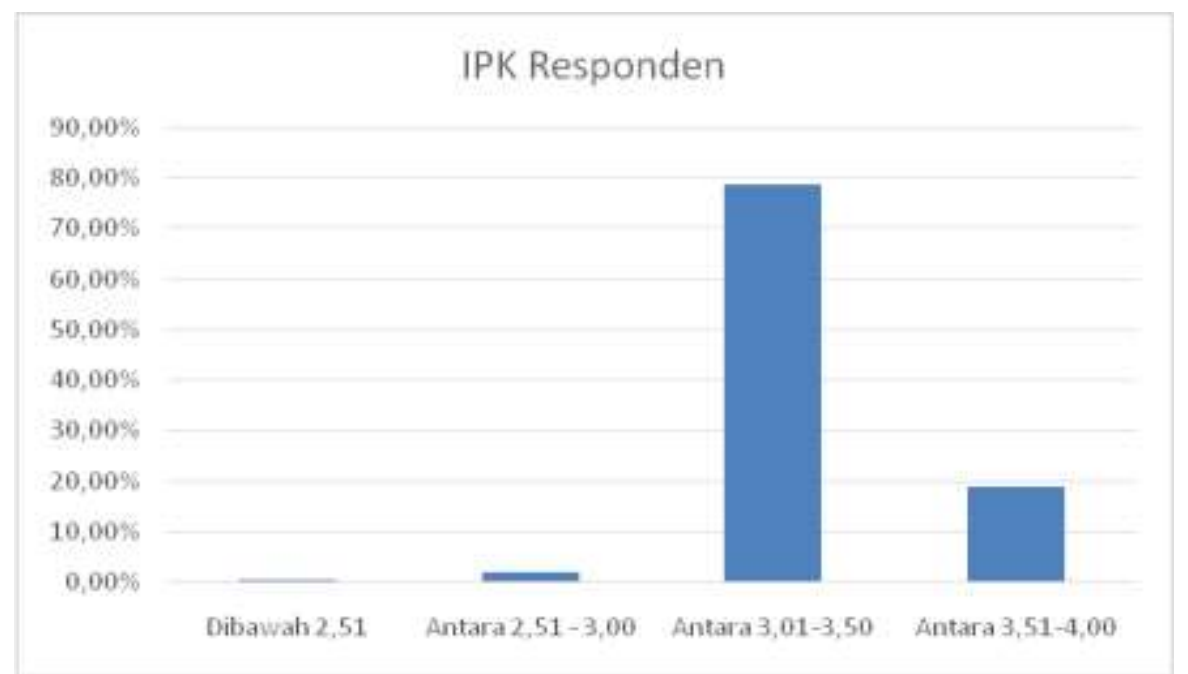

Figure 9: The GPA of the Respondents

From the results correspondent gathered 240, can conclude from the GPA that gets a GPA above 3.0 averages $70 \%$ more, then influence internet usage in the STIP environment has an impact positive for cadets.

\section{Result and Discussion}

The influence of the available Internet, facilities and infrastructure of internet access, factors of internet use and intensity of internet usage simultaneously against learning outcomes.

Based on multiple linear regression tests, it is known that the simultaneous test shows there is an influence with the available internet, internet access facilities and infrastructure, internet usage factors and the intensity of internet usage on learning outcomes, that the higher the internet available, internet access facilities and infrastructure, the factors of internet use and the intensity of internet usage in STIP Jakarta have resulted in increasingly improving learning outcomes. This is evident from the coefficient of determination (R 2) which states together contribute internet available, internet access infrastructure, Internet usage factors and intensity of Internet usage to increase learning outcomes at 0.752 . This figure can be interpreted that $75.2 \%$ of the variance in the learning outcomes variable can be predicted by available internet variables, internet access facilities and infrastructure, internet usage factors and internet usage intensity, while $39.3 \%$ comes from variables other free as a determinant of high learning outcomes.

From the results of testing the significance and linearity it can be concluded that the regression of learning outcomes $-4.127+0.334$ Internet available +0.059 Facilities and infrastructure internet access +0.214 the factors of internet use are very significant and linear, based on these test results available internet variable regression coefficients on learning 
outcomes is 0.334 , facilities and infrastructure for internet access to learning outcomes is 0.059 , the factors of internet use for learning outcomes are 0.214 . The figure reflects that if other regression coefficients other than the internet are available, facilities and infrastructure for internet access, internet usage factors and the intensity of internet use are maintained, then the change in one score given by the internet is available so that the learning outcomes increase by 0.334 , change one score scores on facilities and infrastructure for internet access will have a positive effect of 0.059 , changes in one score of the factors of internet use will have a positive effect of 0.214 units of learning scores with a constant of -4.127 . While the multiple regression test obtained $F$ count $=90.803$ and $\operatorname{sig}(p)=0,000<0.05$. So F count $>F$ table $(90,803>2,479)$, then the third hypothesis is tested. Means that the internet is available, facilities and infrastructure for internet access, internet usage factors and the intensity of internet users have a positive and significant effect on learning outcomes.

\subsection{The influence of the Internet available on learning outcomes}

Based on the results of testing the significance and linearity it was concluded that the available internet variables for learning outcomes were 0.334 . Here it can be seen that the available internet regression coefficients have a positive influence on learning outcomes, available internet regression coefficient of 0.334 means that if the other regression coefficient values are maintained then the change in one available internet score will have a positive effect of 0.334 learning score units with constant $-4,127$. Meaning test using t-test obtained $t$ count of 2.744. Because the value of $t$ count is greater than the value of $t$ table 1.987 , the first hypothesis is tested.

\subsection{Effect of facilities and infrastructure on internet access to learning outcomes}

Based on the results of testing the significance and linearity regression, it was concluded that the results of regression of facilities and infrastructure of internet access with learning outcomes were 0.059 Facilities and infrastructure for internet access, very significant and linear, from the results of the regression coefficients of facilities and infrastructure internet access to learning outcomes was 0.059 . Here it can be seen that the regression coefficients of internet access facilities and infrastructure have a positive influence on learning outcomes. The regression facilities and infrastructure coefficient of internet access amounted to 0.059 means that if the other regression coefficient values are maintained then the change in one score of facilities and infrastructure for internet access will have a positive effect of 0.059 units of learning scores with constants -4.127 . While the significance test uses the t-test obtained by $t$ count of 2.845 . Because the value of $t$ count is greater than the value of $t$ table 1.987 , then the second hypothesis is tested.

\subsection{Effect of internet usage factors against learning outcomes}

Based on the results of testing the significance and linearity regression it can be concluded that the regression results of internet usage factors with learning outcomes of 0.214 are very significant and linear, from the results of these tests the regression coefficients of the factors of internet usage on learning outcomes are 0.214 . Here it can be seen that the regression coefficients of internet usage factors have a positive influence on learning outcomes. The regression coefficient of internet usage factors of 0.214 means that if the other regression coefficient values are maintained then the change in one score value of the factors of internet 
users will have a positive effect of 0.214 units of learning outcome scores with a constant of 4.127. While the significance test uses the t-test obtained t count of 6.576 . Because the value of $\mathrm{t}$ count is greater than the value of $\mathrm{t}$ table 1.987, then the third hypothesis is tested.

\subsection{Effect of internet usage intensity on learning outcomes}

Based on the results of testing the significance and linearity regression it can be concluded that the intensity regression results of internet use with learning outcomes of 0.677 are very significant and linear, from the test results the regression coefficients of the intensity of internet use on learning outcomes are 0.677 . Here it can be seen that the regression coefficient intensity of internet usage has a positive influence on learning outcomes. The regression coefficient of internet usage intensity of 0.677 means that if the other regression coefficient values are maintained then the change in one value of the intensity score of internet usage will give a positive influence of 0.677 units of learning outcomes scores with a constant of -4.127 . While the significance test uses the t-test obtained $t$ count of 6.576 . Because the value of $t$ count is greater than the value of $t$ table 1.987 , then the third hypothesis is tested.

\section{Conclusion}

From the results of testing the hypothesis it is evident that the available internet, facilities, and infrastructure for internet access, internet usage factors and the intensity of internet use both individually and jointly affect the learning outcomes of STIP Jakarta, with the following description:

a. The available internet, facilities, and infrastructure for internet access, internet usage factors and the intensity of internet usage together have a significant effect on learning outcomes at STIP Jakarta.

b. Available internet has a significant effect on learning outcomes at STIP Jakarta.

c. Facilities and infrastructure for internet access have a significant effect on learning outcomes at STIP Jakarta.

d. Internet usage factors have a significant effect on learning outcomes at STIP Jakarta.

e. The intensity of internet usage has a significant effect on learning outcomes at STIP Jakarta.

\section{References}

[1] R. Rahim et al., "Combination Vigenere Cipher and One Time Pad for Data Security," Int. J. Eng. Technol., vol. 7, no. 2.3, p. 92, Mar. 2018.

[2] D. Cameron, Working with spoken discourse. London: SAGE, 2001.

[3] J. Coates, "Talk in a play frame: More on laughter and intimacy," J. Pragmat., vol. 39, no. 1, pp. 29-49, Jan. 2007.

[4] P. Drew and J. Heritage, Analysing talk at work: An introduction. Cambridge: Cambridge University Press, 1992.

[5] K. Hyland, "Genre pedagogy: Language, literacy and L2 writing instruction," $J$. Second Lang. Writ., vol. 16, no. 3, pp. 148-164, Sep. 2007.

[6] Bystrom and Katrina., Task complexity, information types and information sources: examination of relationships. Tampere: Tampere University Press., 1999.

[7] S. Bashir, K. Mahmood, and F. Shafique, "Internet use among university students: a survey in University of the Punjab, Lahore," Pakistan J. Libr. Inf. Sci., vol. 9, no. 1, pp. 49-65, 2008. 
[8] G. . Leckie, K. . Pettigrew, and C. Ylvain, "Modelling the information seeking of professional: a general model derived from research on engineers, health care professionals, and lawyers," Libr. Q., vol. 66, no. 2, 1996.

[9] V. L. Wilburn, Gender and (A)nonymity in Computer-Mediated Communication. New Jersey: Wiley - Blackwell Publishing, 2013.

[10] J. . Horrigan, "New Internet users: What they do online, what they don't, and implications for the net's future," 2002.

[11] E. Nahdiati, "Deskripsi Penggunaan Internet Di Kalangan Mahasiswa Institut Pertanian Bogor,” Institut Pertanian Bogor, 2005. 